\section{DRUNKENNESS AS A CAUSE OF ACCIDENTS. To the Edilor of 'The LANCet.}

Sre,-In confirmation of the "Drunk Statistics" reported in Saturday's LANCET (16th), from the Newcastle Infirmary, I send you the enclosed note from our house-surgeon, who only the week before had, in conversation with me on the subject, stated as much as be now does in writing; and I have no doubt, on inquiry, the same story would be told by every existing hospital in London or the country; at all events it is so at the infirmary here, as I can testify, not for night admissions, but for admissions all round.

I am, Sir, your obedient servant,

Hertford, May 20th, 1874 JOHN WOODHOUSE.

General Infirmary at Hertford, May 18th, 1874.

Dear Sir,-From personal experience I can testify to the fact of the diminution in the number of accidents admitted during the night at St. Bartholomew's Hospital since the passing of "Bruce's Act."

Being the only one of five dressers living in college, I was fortunate enough, during my dressership, to get all the night duty during one week, and generally part, if not all, that of one of the other surgeons.

It is my firm belief that two out of every three accidents (except those occurring amongst the butchers in Sinithfield Meat Market) admitted whilst I was on night duty were caused through drunkenness.

My experience whilst holding other appointments at the hospital during 1871 and 1872 was that the number of night accidents caused by drunkenness had greatly diminished since the public-houses had been closed at eleven o'clock.

If you wish for further evidence, it might be furnished by either of the present house-surgeons who may have held the appointment of dresser before the passing of the Act.

The best evidence of all would, I think, be obtained from the three box-carriers (the fourth being a new man), who will tell you that there are not nearly so many accidents admitted at night as before the ' 71 Act was passed, and that the number of Saturday night "drunks" has considerably diminished.

Dr. Woodhouse.

Yours truly, William Odell.

\section{MR. BRYANT'S LECTURES ON BLOODLESS OPERATING.}

To the Editor of The Lancet.

Sir,-In common, I doubt not, with many of your readers, I have much admired Mr. Bryant's observations " on bloodless operating," but in your last issue he details some cases of "the removal of internal hæmorrhoids by the galvanic cautery," and in these cases I beg to submit, Sir, that in no possible sense can the hæmorrhoids be said to have been removed by the galvanic cautery. Briefly, this is Mr. Bryant's description of the operation:- "When the parts are strained down, the different portions of the bowel to be removed are seized and clamped ; the projecting part is then cut off with scissors, and the galvanic cautery applied so as to form a dry eschar." The piles therefore are not removed by the galvanic cautery, but that apparatus is employed to prevent possible bleeding. How Mr. Bryant can further state that the treatment of hæmorrhoids is much simplified by the introduction of the galvanic cautery is a puzzle to me. Surely the galvanic cautery is not more simple than an iron heated by fre. I have several times seen internal hæmorrhoids really removed by galvanic cautery (in the way I presumed Mr. Bryant meant until I read his lecture) thus: the pile is drawn down, encircled by the platinum wire, which, heated by the battery, cuts through the pile at its base. This operation I am bound to say was in no case, neither immediately nor subsequently, satisfactory.

On analysing Mr. Bryant's cases they do not appear to me to be in any way remarkable, neither for rapidity of recovery nor freedom from pain; in these particulars they singularly differ from the cases which have been from time to time reported by my friend Mr. Henry Smith.

I am, Sir, your obedient servant, WM. Alimingram.

Chandos-street, Cavendish-square, May 16th, 1874.

\title{
TRANSMISSION OF CHOLERA.
}

To the Editor of THE LANCET.

Sin,-At a meeting of the Royal Mredical and Chirurgical Society, a report of which appears in your issue of the 4th ult., Sir William Gull is said to have stated that " cholera did not descend rivers but ascended them, and that this was a fixed and certain law."

In an invasion of epidemic cholera which appeared in Canada about twenty five years ago, and which for some days carried off sixty or seventy of the inhabitants of Quebec daily, the disease unquestionably descended the St. Lawrence from Montreal; and in the regiment of which I had medical charge, and which was then quartered in the citadel of Quebec, none of the hospital attendants were attacked, although many cases were admitted, and there was no indication of spreading by contagion or evacuations. I observed a singular appearance of the atmosphere at the time.

May 19tb, 1874

I remain, Sir, yours, \&c.,

A. M. D.

\section{CRANIOTOMY BY MUNGO PARK.}

To the Editor of THE LANCET.

Sir,-Allow me to correct an error in The LanceT of May 9th. In the report of the proceedings of the Obstetrical Society of London it is said that Dr. Playfair alluded to the case of Mungo Park, upon whom he said "craniotomy" had been performed. This is a mistake. Some years ago I showed to the Obstetrical Society of Edinburgh a woman upon whom craniotomy had been performed by Mungo Park when he was a practitioner in Selkirk.

I am, Sir, yours truly,
Heriot-row, Edinburgh, May 19th, 1874.
JAMES A. SIDEY.

PARIS.

(From our own Correspondent.)

A CROWDED audience lately met at the "Young Men's Christian Association" to hear an eloquent lecture, by Dr. Bateman, of Norwich, on "Darwinism tested by recent researches in language." Sir John Cormack, in introducing the lecturer, made some preliminary remarks on the ingenious speculations of Darwin, which were laid before the scientific world not more than fifteen years ago, and yet had, within that short period, commanded the attention and elicited the critical acumen of the naturalists of all countries. The general public, too, as represented by the pulpit, the press, and the platform, had manifested a strong interest in the subject now popularly known as Darwinism. This could hardly be looked on as very remarkable, if, on the one hand, we considered the surpassing interest attaching to all facts and scientific speculations bearing upon the origin and natural history of the human race; and, on the other hand, the high intellectual ingenuity of the author, and language so essentially beautiful as to char'm even when it failed to convince. Dr. Bateman had not been convinced by the arguments of the great naturalist, and he would presently explain the why and the wherefore. Dr. Bateman had a peculiar right to hold his own views on Darwinism. He had profoundly studied, and, in a masterly manner elucidated, in a published work, the affection called aphasia, and in respect of Darwinism the outcome of his researches was this, - that language was a distinctive attribute of man. The lecturer, after reviewing the main features and general purport of Darwin's work on the "Descent of Man," and calling attention to the author's statement that the difference in mind between man and the lower animals was one of degree only, and not of kind, proceeded to show that man does possess a distinctive attribute of which not a trace cau be found in the ape-an attribute creating an immeasurable gulf between the two. This attribute was the faculty of articulate langrage, and it was the difference of kind of which Darwin was in search. After defining the term language, Dr. Bateman discussed the question as to 